\title{
Smoking and Its Determinants among Iranian Dental Students
}

\author{
M.R. Khami ${ }^{a, c}$ H. Murtomaa ${ }^{c}$ S. Razeghi ${ }^{b} \quad$ J.I. Virtanen ${ }^{c, d}$ \\ ${ }^{a}$ School of Dentistry, Tehran University of Medical Sciences, ${ }^{b}$ School of Dentistry, Qazvin University of Medical \\ Sciences, Tehran, Iran; ' Institute of Dentistry and d Department of Public Health, University of Helsinki, Helsinki, \\ Finland
}

\section{Key Words}

Dental students · Smoking habits · Oral self-care

\begin{abstract}
Objective: The objective of the present study was to investigate smoking habits of Iranian dental students in relation to their background characteristics and oral self-care (OSC).

Subjects and Methods: A survey in the form of a questionnaire was conducted of 327 senior dental students in seven randomly selected state dental schools in Iran. In addition to smoking habits and background characteristics, the students were asked about OSC. A recommended level of OSC was defined as a combination of brushing at least twice a day, frequent use of fluoridated toothpaste, and eating sugary snacks less than daily. Logistic regression models were used to estimate odds ratios (ORs) and 95\% confidence intervals (Cls). A total of 263 students (113 males and 150 females) completely answered the questions and were included in the analyses. Results: Of the 263 students, 59 (23\%, 37 males and 22 females) reported current smoking (cigarette, pipe, or water pipe). Current smoking was associated with male gender $(\mathrm{OR}=2.9,95 \% \mathrm{Cl}=1.4-5.6)$, level of father's education $(\mathrm{OR}=1.4,95 \% \mathrm{Cl}=1.1-1.8)$, and $\mathrm{OSC}(\mathrm{OR}=4.4,95 \% \mathrm{Cl}=1.3-$ 14.9). Conclusion: Smoking among Iranian dental students is similar to their socioeconomic group, and is associated
\end{abstract}

\section{KARGER}

Fax +4161306 1234

E-Mail karger@karger.ch

www.karger.com
(C) 2010 S. Karger AG, Basel

1011-7571/10/0195-0390\$26.00/0

Accessible online at:

www.karger.com/mpp with the characteristics of their background, such as gender and father's level of education, as well as the quality of OSC. The results indicate a need to include smoking cessation education and public health activities in the dental curriculum to provide future health care professionals and role models for patients with adequate training in up-to-date patient management to control smoking.

Copyright $\odot 2010$ S. Karger AG, Basel

\section{Introduction}

Smoking is one of the leading health risks for cancer and cardiovascular and respiratory diseases. In addition to these harmful effects, tobacco use has significant adverse effects on oral health [1]. The harmful effects of smoking oblige oral health professionals to improve performance in treating tobacco dependence. The importance of tobacco control has been emphasized in the WHO Global Oral Health Programme [1].

Historically, dental professionals have not been active in tobacco prevention or treatment of their patients, but recently the role and possibilities of this group in smoking cessation efforts and tobacco control programmes have become more prominent $[1,2]$. Current evidence suggests that performance of these programmes in the dental prac- 
tice setting can be as effective as in other primary health care settings [3, 4]. For example, estimations in the UK have shown that annually between 63,000 and 190,000 smokers would quit the habit if all dentists routinely provided smoking cessation advice to their patients [2].

Success of programmes for cessation of smoking in health care settings depends on the attitude of healthcare professionals towards smoking as well as their preventive orientation. Such orientation is reflected in the smoking habits of the members of this group [5]. The smoking habits of Iranian physicians, medical students and dentists have been reported previously $[6,7]$ but, to our knowledge, no study exists of the smoking habits of dental students, who form an important group of future healthcare professionals. The objective of the present study was to investigate the smoking habits of Iranian dental students in relation to their background characteristics and oral self-care (OSC).

\section{Subjects and Methods}

\section{Study Subjects and Data Collection}

Undergraduate dental education in Iran is based on the national curriculum, which lasts 6 years, and is comprised of basic science (2 years), pre-clinic (1 year), and clinic (3 years) [8]. The target population of this study consisted of senior dental students (those in the last two semesters of their programme) from 15 state dental schools in Iran. To obtain a representative sample, a stratified cluster random sampling approach was implemented. Based on the age of dental schools, two strata were defined: three old schools and four new ones, with 327 senior dental students altogether, were randomly selected to serve as clusters [9]. One of the authors (M.R.K.) visited the selected schools in the spring term of 2005, staying 2 working days in each. A self-administered questionnaire was delivered to all the students in their ordinary classroom settings to be returned immediately [9]. The feasibility of the study method was also tested by conducting a pilot study prior to the main study in one of the excluded schools. Of the 327 students, 270 agreed to participate in the study, and of the 270 students, 263 completely answered the questions and were included in the analysis.

\section{Questions and Variables}

Smoking. Using an anonymous questionnaire, the respondents were asked information on their smoking habits, separately for cigarettes, pipe, and water pipe. The questions had six alternatives [no, never; no, I did but I quit; yes, once a month or less; yes, a few times (2-3) a month; yes, a few times (2-3) a week; yes, once in a day or more]. Based on these alternatives, four categories of respondents were defined: non-smokers (never smoked), ex-smokers (had stopped at the time of the study), occasional smokers (infrequent smokers), and daily smokers (those choosing the last alternative). For further analyses, the first two groups (non-smokers and ex-smokers) were considered as non-smokers, and the last two groups (occasional and daily smokers) were considered as smokers. Since use of smokeless tobacco is rare and limited to some small geographic area in Iran, it was not included in the questionnaire. Of the 270 participating students, 263 (113 males and 150 females) with a mean age of 26 years (range 21-42) completed the questionnaire and were included in the analyses.

Background Information. In addition to giving their gender and year of birth, on two separate questions the students were asked to report their father's and mother's level of education. These questions had eight alternatives (illiterate; able to read and write; primary or secondary school education; high school or vocational school education; Associate's degree; Bachelor's degree; Master's degree; doctorate). The students were also requested to report if they had a parent employed in dentistry and if they had a dental hygienist degree before entering dentistry.

Oral Self-Care. The respondents were requested to report the frequency with which they brushed their teeth, used fluoridated toothpaste, flossed and ate sugary snacks between main meals, as previously defined $[10,11]$. These questions had from four to seven alternatives [9]. In order to define acceptable levels of each of the OSC components, the following criteria were used: brushing at least twice a day, using fluoridated toothpaste always or almost always, flossing at least once a day, and eating sugary snacks between main meals less frequently than once a day. A recommended level of OSC was defined as a combination of brushing more than once a day, using fluoridated toothpaste always or almost always, and eating sugary snacks less than daily, as previously described [10].

\section{Statistical Methods}

The data were analysed using SPSS for Windows, version 11.5 (Chicago, Ill., USA). Logistic regression model was fitted to the data to measure the strength of association of outcome measure with explanatory factors and to calculate corresponding odds ratios (ORs) and 95\% confidence intervals (CIs).

\section{Results}

Fifty-nine (23\%) students, of whom 37 were male and 22 female, reported current cigarette, pipe or water pipe smoking, either occasionally (16\%) or daily (7\%). The most common smoking habit among both males and females was occasional water pipe smoking (20 and 13\% respectively), followed by daily cigarette smoking among men $(12 \%)$. On the other hand, none of the women reported daily pipe or water pipe smoking (table 1).

Compared to non-smokers, students who smoked reported lower frequencies of twice-a-day tooth brushing, frequent use of fluoridated toothpaste, once-a-day flossing, and less than daily consumption of sugary snacks (table 2). None of the differences, however, were significant. Fulfilling the criteria for recommended OSC was significantly less common among female smokers compared to non-smokers ( 5 vs. $23 \%$, p < 0.05 ). The difference among male students and non-smokers in this regard was not statistically significant. 
Table 1. Various smoking habits reported by Iranian dental students $(n=263)$

\begin{tabular}{|c|c|c|c|c|c|c|c|}
\hline & \multirow[t]{2}{*}{ All } & \multicolumn{2}{|l|}{ Cigarettes } & \multicolumn{2}{|l|}{ Pipe } & \multicolumn{2}{|l|}{ Water pipe } \\
\hline & & $\operatorname{men}(n=113)$ & women $(n=150)$ & $\operatorname{men}(n=113)$ & women $(n=150)$ & $\operatorname{men}(n=113)$ & women $(n=150)$ \\
\hline Non-smokers & $192(73 \%)$ & $80(71 \%)$ & $137(91 \%)$ & $94(83 \%)$ & 147 (98\%) & $80(71 \%)$ & $128(85 \%)$ \\
\hline Ex-smokers & $12(4 \%)$ & $10(9 \%)$ & $3(2 \%)$ & $14(12 \%)$ & $1(1 \%)$ & $9(8 \%)$ & $3(2 \%)$ \\
\hline Occasional smokers & $40(16 \%)$ & $9(8 \%)$ & $6(4 \%)$ & $4(4 \%)$ & $2(1 \%)$ & $23(20 \%)$ & $19(13 \%)$ \\
\hline Daily smokers & $19(7 \%)$ & $14(12 \%)$ & $4(3 \%)$ & $1(1 \%)$ & $0(0 \%)$ & $1(1 \%)$ & $0(0 \%)$ \\
\hline
\end{tabular}

Of the 270 participating students, 263 completely answered the smoking questions.

Table 2. OSC components as reported by smoker and non-smoker Iranian dental students $(\mathrm{n}=263)$

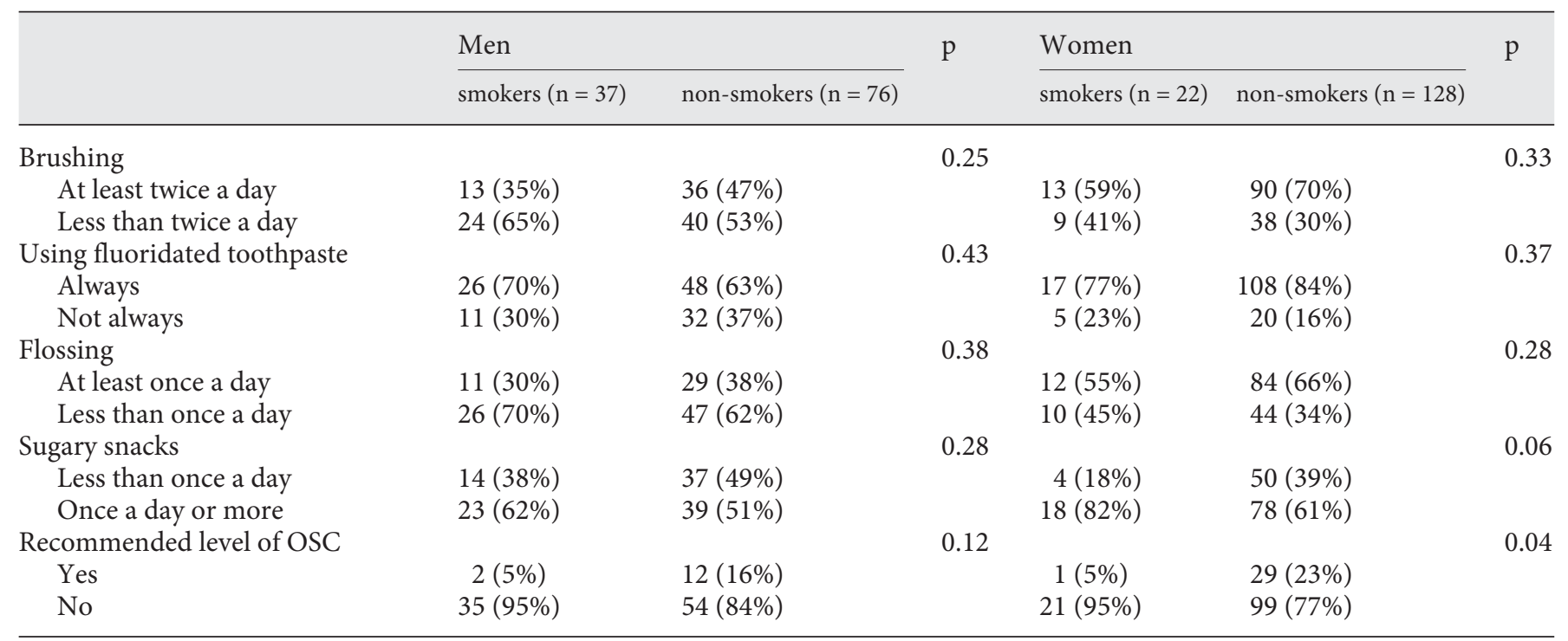

Of the 270 participating students, 263 completely answered the OSC questions and were included in the analyses. p values derived from $\chi^{2}$ test.

Current smoking was associated with male gender $(\mathrm{OR}=2.9,95 \% \mathrm{CI}=1.4-5.6)$ and higher levels of father's education $(\mathrm{OR}=1.4,95 \% \mathrm{CI}=1.1-1.8)$ in the binary logistic regression model (table 3 ). The students who fulfilled the criteria for OSC were less likely to report current smoking than those who did not $(\mathrm{OR}=4.4,95 \% \mathrm{CI}=$ 1.3-14.9).

\section{Discussion}

The results of the present study showed that smoking among Iranian dental students is common and particularly characterized by a high incidence of water pipe smoking. The results also showed that smoking was associated with the background characteristics of dental students, such as gender and father's level of education as well as the quality of OSC.

Self-reported smoking among the Iranian general population in a national survey has been reported to be $17.4 \%$ for high-school students [12], $8.5 \%$ for 16 - to 25 -year-olds [13], $18.3 \%$ for male and 1.3 for female 19 - to 49 -year-olds [14]. One would expect that dental students, as health professionals with more knowledge about the harmful effects of smoking and future specialists in oral health, would report lower smoking rates compared to the lay population. On the other hand, our results are comparable to the reported smoking prevalence among 
Table 3. Factors related to smoking among Iranian dental students $(n=263)$ in a logistic regression model ${ }^{\mathrm{a}}$

\begin{tabular}{|c|c|c|c|}
\hline & $\mathrm{p}$ & OR & $95 \% \mathrm{CI}$ \\
\hline Gender (1: women, 2: men) & 0.003 & 2.9 & $1.4-5.6$ \\
\hline Parent job (1: non-dentist, 2: dentist) & 0.80 & 0.9 & $0.3-2.7$ \\
\hline \multicolumn{4}{|l|}{ Dental hygienist background } \\
\hline (1: no, $2:$ yes $)$ & 0.50 & 1.5 & $0.5-4.2$ \\
\hline Father's level of education ${ }^{\mathrm{b}}$ & 0.02 & 1.4 & $1.1-1.8$ \\
\hline Mother's level of education ${ }^{\mathrm{b}}$ & 0.31 & 0.9 & $0.7-1.1$ \\
\hline \multicolumn{4}{|l|}{ Fulfilled criteria for recommended } \\
\hline OSC (1: yes, $2:$ no) & 0.02 & 4.4 & $1.3-14.9$ \\
\hline Constant & 0.00 & & \\
\hline
\end{tabular}

Outcome variable: 0 = non-smoking (combination of nonsmoking and ex-smoking), 1 = smoking (combination of occasional and daily smoking). Of the 270 participating students, 263 completely answered the OSC questions and were included in the analyses. Hosmer-Lemeshow goodness-of-fit test significance $\mathrm{p}=$ 0.4 for the model; reference category is italicized.

${ }^{\text {a }}$ ORs are adjusted for other explanatory variables presented in the table.

${ }^{\mathrm{b}}$ Alternatives: 1 = illiterate, $2=$ able to read and write, $3=$ primary or secondary school education, $4=$ high school or vocational school education, $5=$ Associate's degree, $6=$ Bachelor's degree, $7=$ Master's degree, $8=$ doctorate.

Iranian dentists (24\%) [7] and male dental school educators (22\%) [15], while lower rates have been reported for Iranian attending physicians (7.5\%) and senior medical students (17\%) [6]. However, a high proportion of smokers among the future dentists seem to be in disharmony with the current emphasis on the interventional role of oral healthcare professionals in smoking cessation programmes $[1,2]$.

As may be expected, a great variation exists in the reported prevalence of smoking among dental students in various countries, ranging from $13 \%$ in Australia [16] to $37.3 \%$ in Romania [17]. Smoking prevalence in our sample (23\%), being approximately the same level as Ireland (20\%) [18], Belgium (25\%) [19] and Jordan (17\%) [20], can in any case be considered as alarmingly high. It is worth noting that the participants of almost all the earlier studies were dental students of all grades, while our participants were senior dental students usually with higher rates of smoking compared to freshmen [17].

In our sample, the dominant smoking habit among both male and female smokers was water pipe smoking. This pattern is consistent with that of the general population [12]. That only $3 \%$ of women were daily cigarette smokers, being consistent with data from Iranian dentists
[7], dental school educators [15] and the lay population [12-14], showed that cigarette smoking still is an unattractive behaviour among Iranian women. On the other hand, higher prevalence of water pipe smoking among women indicated the more social acceptability of water pipe smoking compared to cigarette smoking, especially among women in Iran [12]. This could be cause for concern. The availability of water pipes in traditional teahouses, which has been shown to be the first place for smoking experience among Iranian girls, and the opportunity girls have to try the water pipe as a traditional fun [12] can explain these results. Recently, the Iranian government has passed several rules to ban the provision of water pipes in public places.

Implementation of multi-stage sampling, presence of one of the researchers in all selected dental schools, and performance of a pilot study served as strategies to increase the validity of the study. Stratified random sampling resulted in a relatively high response rate $(81 \%)$. The three private dental schools were excluded because of problems with comparability resulting from differences related to entrance examination, students' background and characteristics $[9,21]$.

Although the questionnaires were completed anonymously, it should be noted that in Iran, cigarette smoking is an unattractive social behaviour, especially among women [12]. Thus, arising from a self-administered questionnaire, the results of the study should be interpreted cautiously due to the problem of the respondents' attitude toward the social acceptability of the behaviour surveyed [22]. For this reason, the present results should be considered to be more of an underestimation than overestimation of the behaviours studied.

The finding that smoking was significantly more prevalent among men compared to women is consistent with many other studies of dental students $[17,20]$, other oral health professionals [7, 15], and the Iranian lay population [12-14]. Besides the social acceptability mores explained above, this finding may show that women put more value on their health and are not necessarily concerned by the social stigma. Studies of OSC among Iranian dental students [9], dentists [7], and dental school educators [15] also show more favourable behaviour among women compared to men.

In the present study smoking habits were associated with a higher level of education of the student's father. This finding is in contrast with a previous study identifying lower education of fathers as a possible determinant of smoking among Iranian youths [23]. Probable differences in socioeconomic background in our sample com- 
pared with the previous local study, in addition to higher ages of our sample, may explain this finding.

Good oral hygiene was significantly associated with absence of smoking habit among dental students. Existence of the same pattern among Iranian dentists [7] and dental school educators [15] provides a good basis for prevention, and hopefully, also for success of smoking cessation programmes in dental practice settings. Studies on attitudes of dental students towards smoking cessation activities in dental practice settings generally have reported positive results $[24,25]$. These findings emphasize the role of dental schools in educating preventive-oriented dentists for Iran, as suggested previously [15]. Moreover, public health measures such as legislation and policy-making to control smoking at the community level should be addressed in dental education.

\section{Conclusion}

Smoking among Iranian dental students is associated with poor OSC habits; it is fairly common and similar to the smoking habits of their counterparts in the general population. All dental students should be made aware of the health hazards related to smoking and efforts to promote non-smoking should be supported. With the current emphasis on the dentists' role in smoking cessation, the results call for a need to include smoking cessation activities in the national dental curriculum.

\section{Acknowledgement}

This research was partly supported by a grant from the Iranian Center for Dental Research (ICDR), Shahid Beheshti Dental School, Tehran, Iran.

\section{References}

$\checkmark 1$ Petersen PE: Tobacco and oral health - the role of the World Health Organization. Oral Health Prev Dent 2003;1:309-315.

-2 Watt RG, Johnson NW, Warnakulasuriya KA: Action on smoking - opportunities for the dental team. Br Dent J 2000;189:357-360.

-3 Carr AB, Ebbert JO: Interventions for tobacco cessation in the dental setting: a systematic review. Community Dent Health 2007; 24:70-74.

4 Warnakulasuriya S: Effectiveness of tobacco counseling in the dental office. J Dent Educ 2002;66:1079-1087.

5 Johnson NW: The role of the dental team in tobacco cessation. Eur J Dent Educ 2004; 8(suppl 4):18-24.

6 Ahmadi J, Khalili H, Jooybar R, Namazi N, Aghaei PM: Cigarette smoking among Iranian medical students, resident physicians and attending physicians. Eur J Med Res 2001;28:406-408.

7 Ghasemi H, Murtomaa H, Vehkalahti MM, Torabzadeh H: Determinants of oral health behaviour among Iranian dentists. Int Dent J 2007;57:237-242.

$\checkmark 8$ Pakshir HR: Dental education and dentistry system in Iran. Med Princ Pract 2003;12 (suppl 1):56-60.

-9 Khami MR, Virtanen JI, Jafarian M, Murtomaa H: Oral health behaviour and its determinants amongst Iranian dental students. Eur J Dent Educ 2007;11:42-47.

10 Tseveenjav B, Vehkalahti M, Murtomaa H: Oral health and its determinants among Mongolian dentists. Acta Odontol Scand 2004;62:1-6.
11 Murtomaa H, Turtola L, Rytomaa I: Use of dental floss by Finnish students. J Clin Periodontol 1984;11:443-447.

12 Kelishadi R, Ardalan G, Gheiratmand R, Majdzadeh R, Delavari A, Heshmat R, Mokhtari MR, Razaghi EM, Motaghian M, Ahangar-Nazari I, Mahmood-Arabi MS, Barekati H (CASPIAN Study Group): Smoking behavior and its influencing factors in a national-representative sample of Iranian adolescents: CASPIAN study. Prev Med 2006;42:423-426.

-13 Ahmadi J, Khalili H, Jooybar R, Namazi N, Mohammadagaei P: Prevalence of cigarette smoking in Iran. Psychol Rep 2001;89:339341.

14 Sarraf-Zadegan N, Boshtam M, ShahrokhiS, Naderi GA, Asgary S, Shahparian M, Tafazoli F: Tobacco use among Iranian men, women and adolescents. Eur J Public Health 2004; 14:76-78.

15 Khami MR, Virtanen JI, Jafarian M, Murtomaa H: Oral health behaviour of Iranian dental school educators. Oral Health Prev Dent 2006;4:265-271.

16 Rikard-Bell G, Groenlund C, Ward J: Australian dental students' views about smoking cessation counseling and their skills as counselors. J Public Health Dent 2003;63: 200-206.

17 Dumitrescu AL: Attitudes of Romanian dental students towards tobacco and alcohol. J Contemp Dent Pract 2007;8:64-71.
18 McCartan BE, Sadlier D, O'Mullane DM: Smoking habits and attitudes of Irish dentists and dental students. J Ir Dent Assoc 1993;39:26-29.

19 Vanobbergen J, Nuytens P, van Herk M, De Visschere L: Dental students' attitude towards anti-smoking programmes: a study in Flanders, Belgium. Eur J Dent Educ 2007;11: 177-183.

20 Al-Omari QD, Hamasha AA: Gender-specific oral health attitudes and behavior among dental students in Jordan. J Contemp Dent Pract 2005;15:107-114.

21 Khami MR, Virtanen JI, Jafarian M, Murtomaa H: Prevention-oriented practice of Iranian senior dental students. Eur J Dent Educ 2007;11:48-53

-22 Sjöström O, Holst D: Validity of a questionnaire survey: response patterns in different subgroups and the effect of social desirability. Acta Odontol Scand 2002;60:136-140.

- 23 Kelishadi R, Mokhtari MR, Tavasoli AA, Khosravi A, Ahangar-Nazari I, Sabet B, Kazemi A, Amini A: Determinants of tobacco use among youths in Isfahan, Iran. Int J Public Health 2007;52:173-179.

24 Cannick GF, Horowitz AM, Reed SG, Drury TF, Day TA: Opinions of South Carolina dental students toward tobacco use interventions. J Public Health Dent 2006;66:44-48.

25 Polychonopoulou A, Gatou T, Athanassouli T: Greek dental students' attitudes toward tobacco control programmes. Int Dent J 2004;54:119-125. 